\title{
PERANCANGAN APLIKASI ADMINISTRASI SISWA PADA SMK AI-MUHAJIRIN DI DEPOK BERBASIS JAVA NETBEANS
}

\author{
Widya Mauriska Rizal ${ }^{1}$, Nico Bustanul ${ }^{2}$, Bertha Meyke W. Hutajulu ${ }^{3}$ \\ ${ }_{1,2,3}$ Fakultas Teknik dan Ilmu Komputer, Universitas Indraprasta PGRI \\ 1widyamauriskarizalsoebowo97@gmail.com
}

\begin{abstract}
Abstrak
Tujuan penelitian adalah untuk merancang aplikasi administrasi siswa pada SMK Al-Muhajirin menjadi sistem teraplikasi agar dapat mempercepat proses rekapitulasi dan penyusunan laporan, serta meminimalisir terjadinya keterlambatan pembuatan laporan. Metode penelitian yang digunakan oleh peneliti dalam penelitian ini adalah metode Grounded Research untuk mengembangkan suatu sistem administrasi atau menyempurnakan sistem administrasi yang telah ada agar dapat berfungsi untuk meningkatkan efektifitas kerja pada SMK Al-Muhajirin. Perancangan Aplikasi administrasi menggunakan MySQL sebagai database dan Java Netbeans.
\end{abstract}

Kata Kunci: Aplikasi, Administrasi, Java Netbeans

\begin{abstract}
The research objective is to design student administration applications at AlMuhajirin Vocational School to be an applied system in order to accelerate the process of recapitulation and preparation of reports, as well as minimize the occurrence of delays in making reports. The research method used by researchers in this study is the Grounded Research method to develop an administrative system or improve an existing administrative system so that it can function to improve the effectiveness of work at SMK Al-Muhajirin. The administration application design uses MySQL as a database and Java Netbeans.
\end{abstract}

Keywords: Application, Administration, Java Netbeans

\section{Pendahuluan}

Perkembagan teknologi dan kebutuhan akan informasi yang semakin meningkat saat ini,tentu saja memerlukan sebuah pelayanan akan pengolahan data yang sangat cepat dan tepat. Dimana suatu teknologi yang digunakan untuk mengolah data, termasuk memproses, mendapatkan, menyusun, menyimpan, manipulasi data dalam berbagai cara untuk menghasilkan informasi yang berkualitas, yaitu informasi yang relevan, akurat dan tepat waktu yang dapat digunakan untuk keperluan pribadi, bisnis, dan pemerintahan. Dengan melihat perkembangan teknologi yang semakin maju penulis mencoba untuk membantu permasalahan yang sering terjadi, penulis melihat pada SMK Al-Muhajirin yang memiliki kelemahan dalam sistem pembayaran sekolah. Hal ini dikarenakan dalam pengolahan data yang digunakan masih manual sehingga masih banyak masalah yang di hadapi seperti efisiensi waktu dan tenaga yang dikeluarkan untuk biaya penggadaan data, penulisan data dan pencarian informasi siswa. Untuk itu penulis memberikan solusi agar sistem pembayaran sekolah bekerja secara optimal sehingga sistem pengolahan data dapat berjalan secara cepat dan tepat. Supaya pembayaran biaya sekolah ini, dapat memperlancar kinerja pembelajaran dan menyediakan fasilitasfasilitas yang di perlukan oleh para siswa. 


\begin{abstract}
Adapun tujuan penelitian ini adalah Merancang sebuah aplikasi sistem administrasi pembayaran sekolah dalam pengolahan data untuk mencapai hasil yang cepat, tepat dan akurat serta digunakan secara berkelanjutan. Mengurangi tingkat kesalahan penginputan data dan pengecekan data dan dapat membantu dalam pembuatan aplikasi perancangan sistem administrasi pembayaran sekolah sehingga menghasilkan informasi yang akurat.
\end{abstract}

\section{Metode Penelitian}

Dalam melakukan penelitian tersebut senantiasa diperlukan suatu metode penelitian yang sesuai dengan pokok permasalahan yang akan diteliti, sedangkan metode penelitian itu sendiri menurut (Sugiyono, 2013) menjelaskan bahwa metode penelitian merupakan cara ilmiah untuk mendapatkan data dengan tujuan dapat ditemukan, dikembangkan dan dibuktikan suatu pengetahuan tertentu sehingga pada gilirannya dapat digunakan untuk memahami, memecahkan, dan mengantisipasi masalah dalam bidang bisnis.

Metode penelitian yang digunakan peneliti adalah metode grounded research, yaitu suatu metode penelitian berdasarkan pada fakta dan empiris, menetapkan konsep, membuktikan teori, mengembangkan teori, pengumpulan, dan menganalisa data dalam waktu yang bersamaan. Dalam riset ini data merupakan sumber teori atau teori berdasarkan data.

Metode pengumpulan data yang dilakukan oleh peneliti untuk mendapatkan data-data serta informasi untuk mendukung penyempurnaan hasil dari penelitian ini antara lain:

\section{Studi Kepustakaan}

Pengumpulan data dan informasi dari kutipan-kutipan buku-buku peraturan perundang-undangan, serta hasil laporan dan hukum lainnya yang berkaitan dengan penelitian ini. Penulis melakukan studi kepustakaan berdasarkan referensi dari berbagai diskusi pembahasan baik dengan dosen pembimbing maupun dengan orang yang berkompeten pada kasus ini. Studi kepustakaan bertujuan untuk mempelajari dan memahami dasar teori yang berhubungan dengan analisa kebutuhan yang telah dilakukan.

\section{Studi Lapangan}

Bertempat di SMK Al-Muhajirin Depok. Peneliti lakukan studi lapangan untuk melihat langsung terhadap Sistem Administrasi Siswa. Dalam studi lapangan ini dipergunakan teknik pengumpulan data antara lain dengan cara survei dan wawancara.

\section{Hasil dan Pembahasan}

Menurut (Sutabri, 2016) "Rancangan Data Flow Diagram (DFD) adalah suatu network yang menggambarkan suatu system automat atau komputerisasi, manualisasi, atau gabungan dari keduanya, yang penggambarannya disusun dalam bentuk kumpulan komponen sistem yang saling berhubungan sesuai aturan mainnya." Berikut adalah rancangan DFD yang peneliti usulkan:

\section{Diagram Konteks}

Diagram ini dibuat untuk menggambarkan sumber serta tujuan data yang akan di proses atau kata lain diagram tersebut digunakan untuk menggambarkan sistem secara umum atau global dari keseluruhan sistem yang ada. 


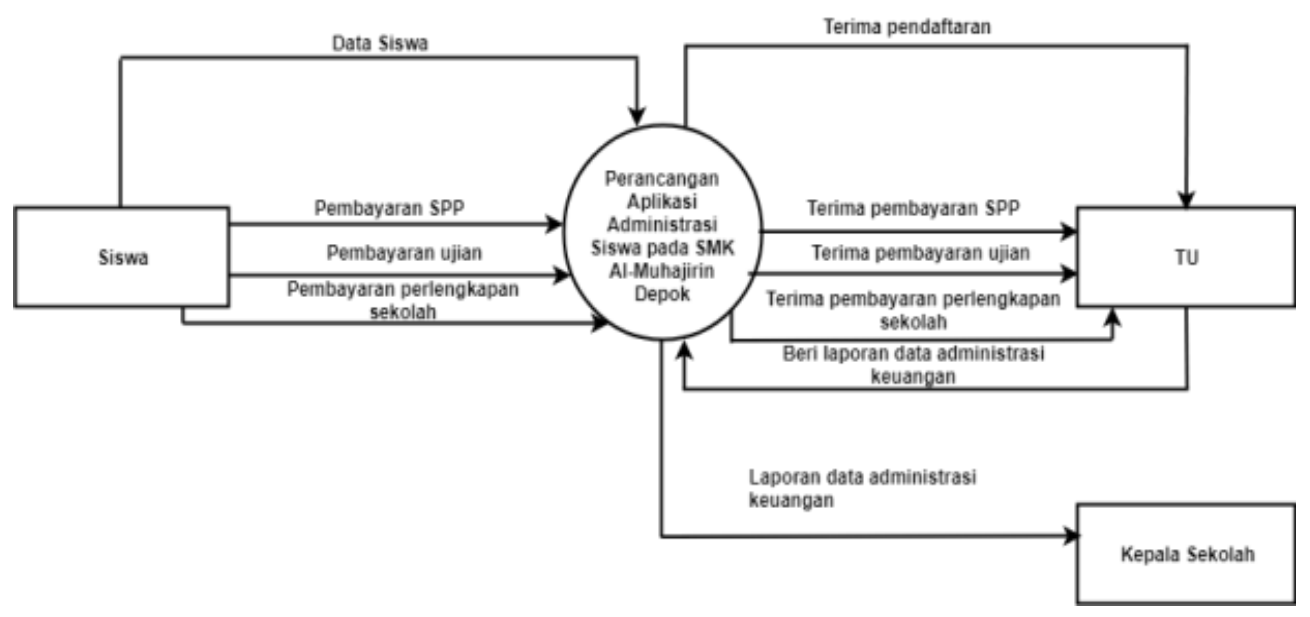

Gambar.1 Diagram Konteks yang Diusulkan

\section{Diagram Nol}

Diagram ini dibuat untuk menggambarkan tahapan proses yang ada didalam diagram konteks, yaitu penjabarannya lebih terperinci. Tahapan proses tersebut diantranya adalah:

\section{2)Pembayaran SPP}

3)Pembayaran Ujian

4)Pembayaran Perlengkapan Sekolah 5)Laporan

1)Siswa

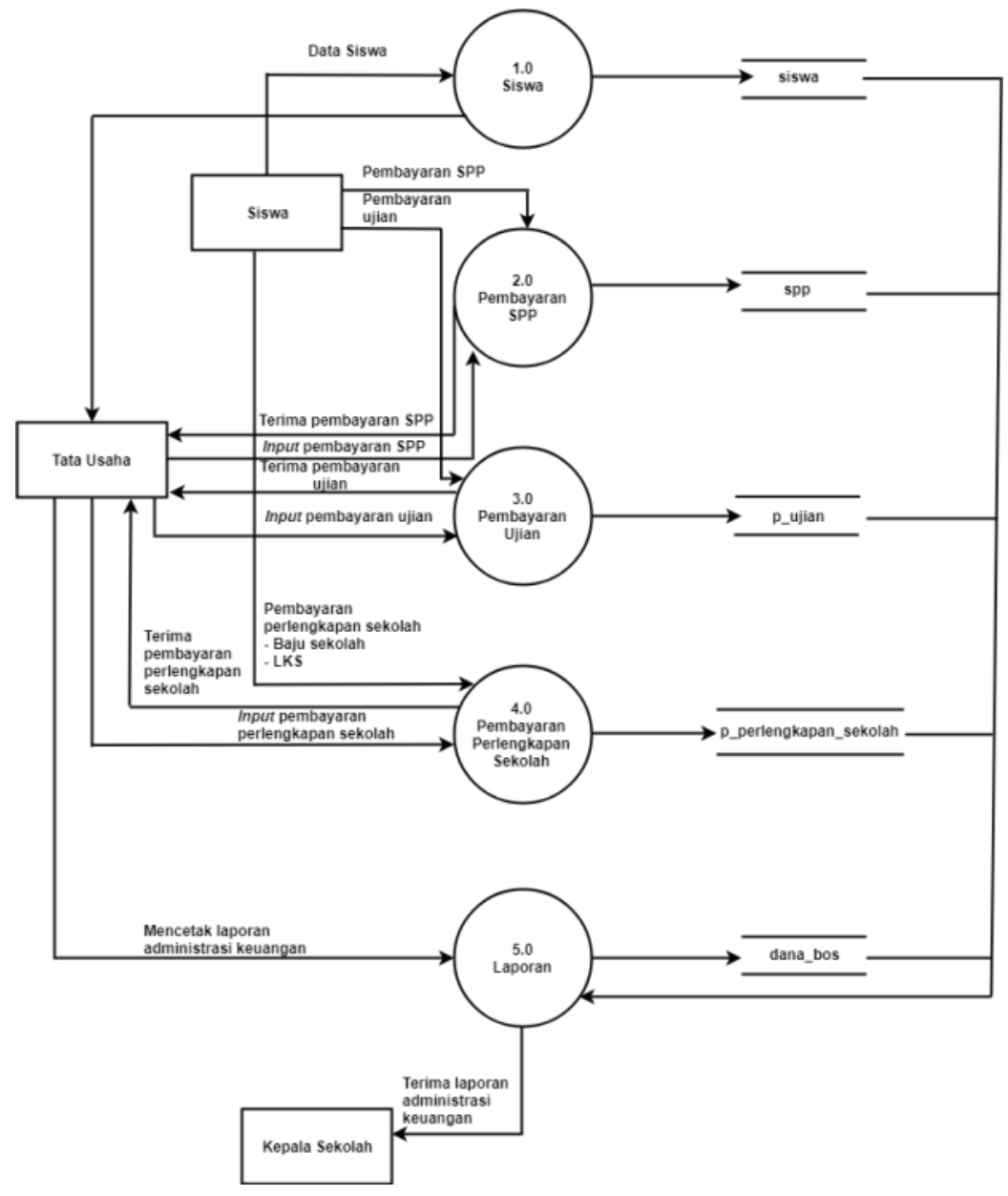

Gambar.2 Diagram Nol yang Diusulkan 


\section{Normalisasi}

Menurut (Yakub, 2012), normalisasi adalah salah satu cara pendekatan atau teknik yang digunakan dalam membangun desain logic basis data relation dengan menerapkan sejumlah aturan dan kriteria standar. Tujuan dari normalisasi adalah untuk menghasilkan struktur table yang normal dan baik. Berikut adalah normalisasi yang peneliti buat :
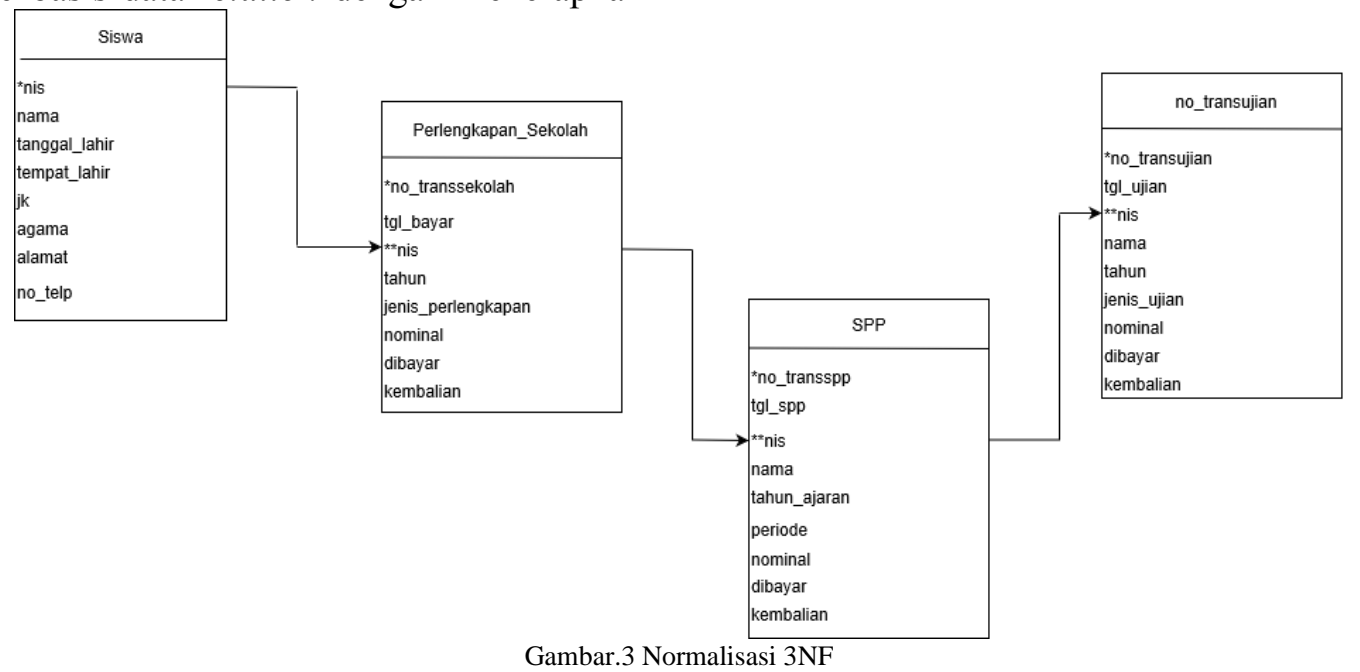

\section{Entity Relationship Diagram (ERD)}

Menurut Robi Yanto (2016:23), Entity Relationship Diagram (ERD) adalah suatu diagram untuk menggambarkan konseptual dari model konseptual suatu basis data relasional.

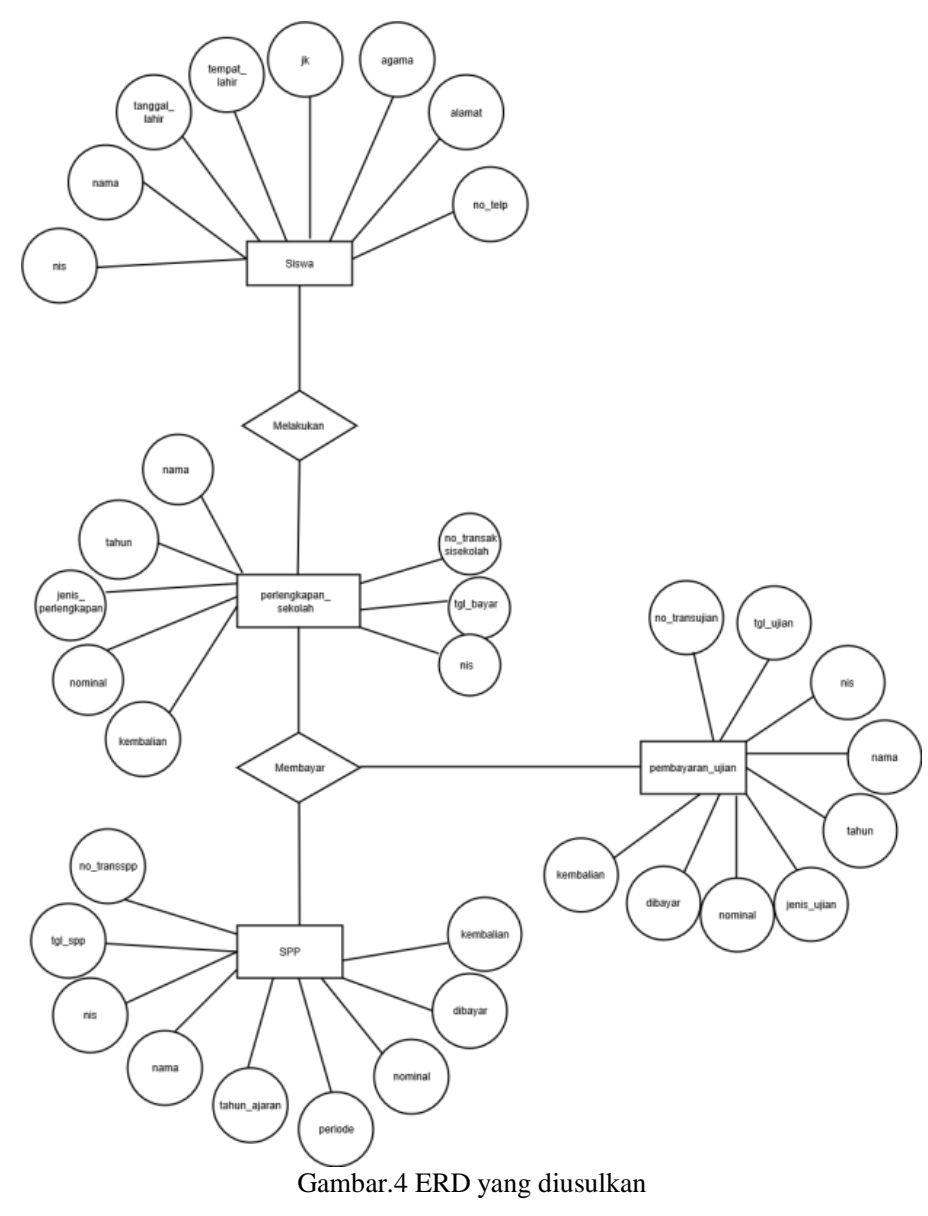


Selanjutnya penulis membuat aplikasi menggunakan java dan database mysql. Berikut ini adalah tampilan dari Perancangan Aplikasi Administrasi Siswa pada SMK AlMuhajirin:

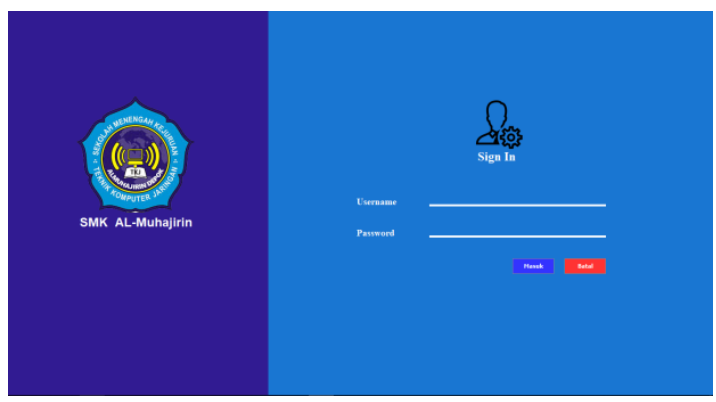

Gambar 5. Login

Tampilan form login ini muncul di awal saat pengoprasian program sistem aplikasi administrasi siswa .untuk diisi oleh admin sebagai user. Masukkan username dan password yang sesuai dengan hak akses supaya bisa mengoprasikan sistem aplikasi administrasi siswa. Jika username dan password sesuai, maka akan masuk kepada tampilan Menu Utama.

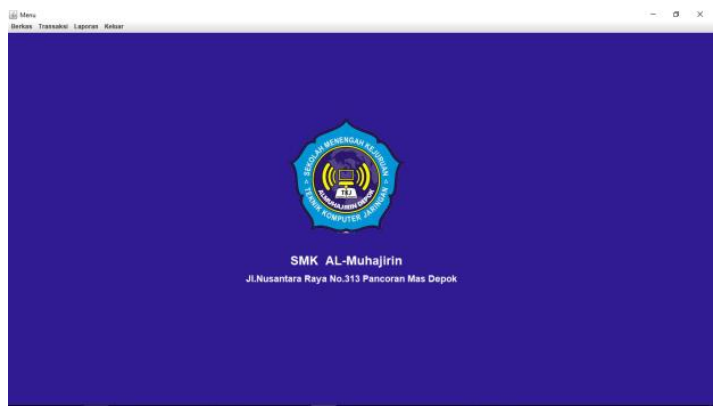

Gambar 6. Menu Utama

Tampilan Menu Utama ini terdapat beberapa icon menu yang akan menampilkan form-form masukkan data diantaranya:

a. Data siswa, akan menampilkan input data siswa.

b. Pembayaran SPP, akan menampilkan input pembayaran SPP.

c. Ujian, akan menampilkan input pembayaran ujian.

d. Pembayaran perlengkapan sekolah, akan menampilkan input pembayaran perlengkapan sekolah. e. Laporan, akan menampilkan data laporan data siswa, pembayaran spp, pembayaran ujian, dan pembayaran perlengkapan sekolah.

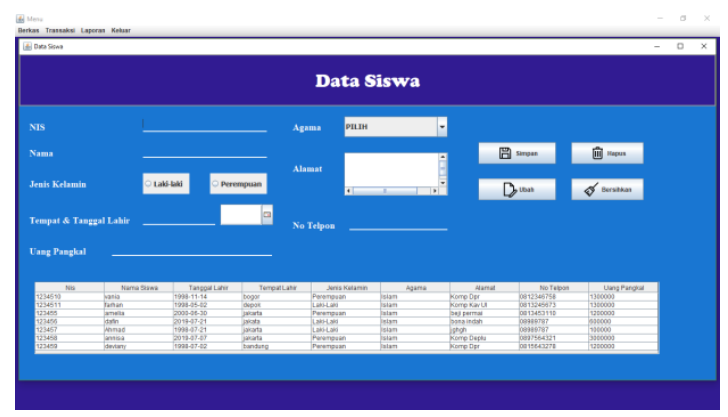

Gambar 7. Tampilan Menu Data Siswa

Tampilan Form data siswa ini, user dapat melakukan penambahan data siswa, mengubah, dan menghapus data siswa. Masukkan NIS untuk melakukan pengecekan data-data yang sudah tersimpan. Lakukan pengisian apabila akan dilakukan penambahan data dan tekan tombol (simpan) untuk menyimpan data, untuk memperbaharui data tombol (ubah), dan untuk menghapus data klik tombol (hapus). Untuk mengahapus data yg belum di save di form, klik tombol (bersihkan)

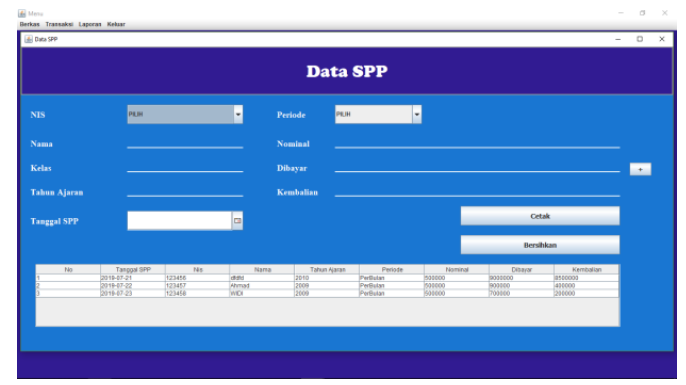

Gambar 8. Tampilan Data SPP

Tampilan Form data spp ini, user dapat melakukan pembayaran data pembayaran spp, Pilih NIS siswa untuk melakukan pembayaran. Tekan tombol (cetak) untuk mencetak pembayaran spp, dan untuk menghapus data klik tombol (delete). 


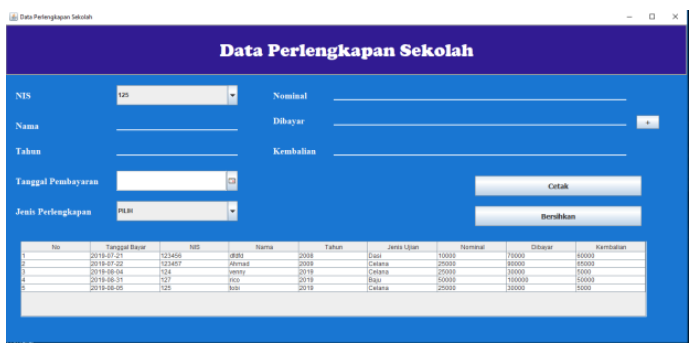

Gambar 9. Tampilan Data Perlengkapan Sekolah

Tampilan Form data perlengkapan sekolah ini, user dapat melakukan pembayaran data pembayaran perlengkapan sekolah, Pilih NIS siswa untuk melakukan pembayaran. Tekan tombol (cetak) untuk mencetak pembayaran spp, dan untuk menghapus data klik tombol (delete).

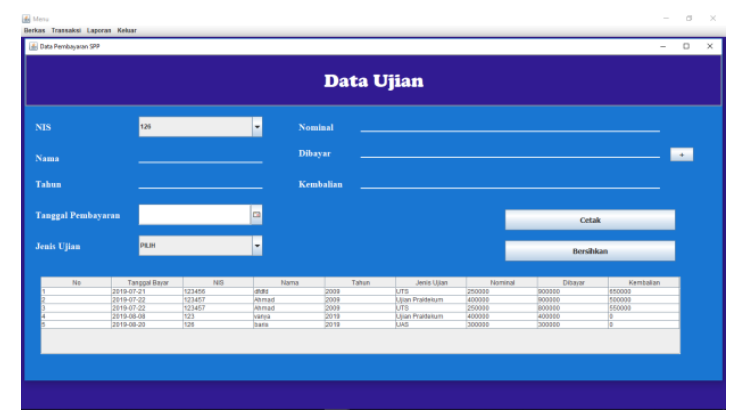

Gambar 10. Tampilan Data Pembayaran Ujian

Tampilan Form data Ujian ini, user dapat melakukan pembayaran data pembayaran ujian, Pilih NIS siswa untuk melakukan pembayaran. Tekan tombol (cetak) untuk mencetak pembayaran ujian, dan untuk menghapus data klik tombol (bersihkan).

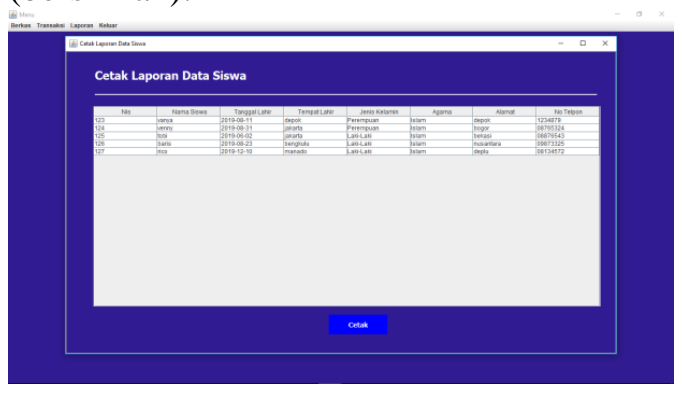

Gambar 11. Tampilan Laporan Data Siswa

Tampilan Laporan data siswa ini, user akan mencetak laporan data siswa yang akan diserahkan kepada kepala sekolah dan untuk mencetak data klik tombol (cetak).

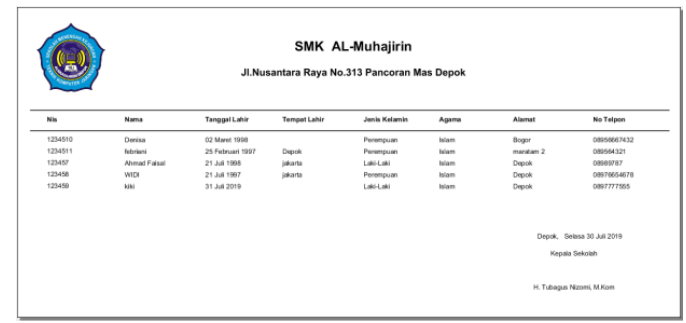

Gambar 12. Output Laporan Data Siswa

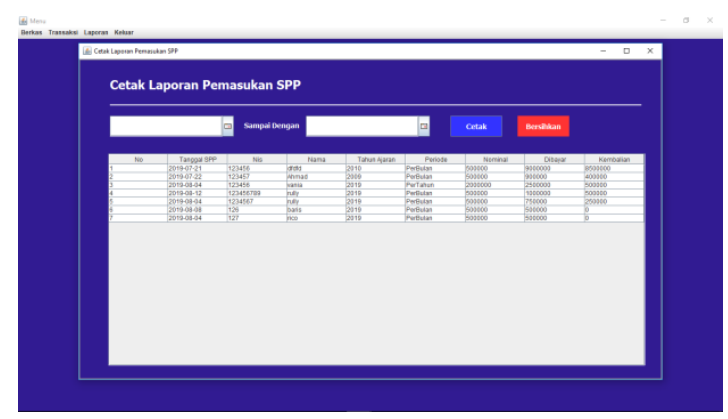

Gambar 13. Tampilan Laporan SPP

Tampilan Laporan data pembayaran spp, user akan memilih tanggal laporan data pembayaran yang akan diserahkan kepada kepala sekolah, untuk mencetak data klik tombol (cetak) dan untuk menghapus data klik tombol (bersihkan) .

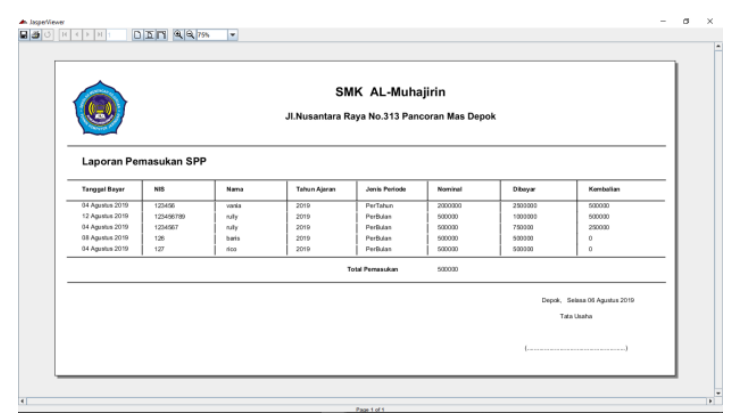

Gambar 14. Output Laporan Data Pembayaran SPP

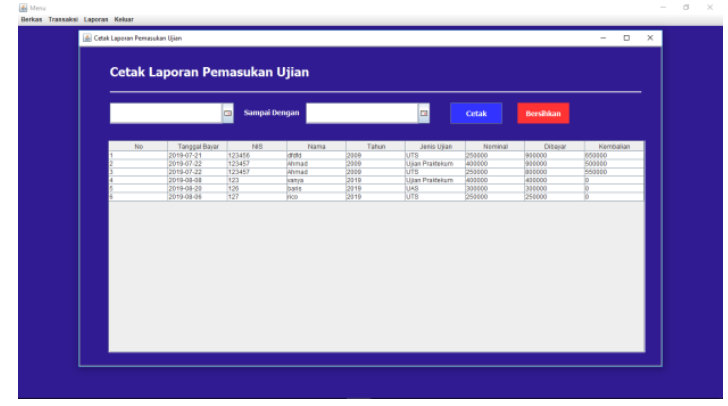

Gambar 15. Tampilan Laporan Data Pembayaran Ujian 
Tampilan Laporan data pembayaran ujian, user akan memilih tanggal laporan data pembayaran ujian yang akan diserahkan kepada kepala sekolah, untuk mencetak data klik tombol (cetak) dan untuk menghapus data klik tombol (bersihkan) .

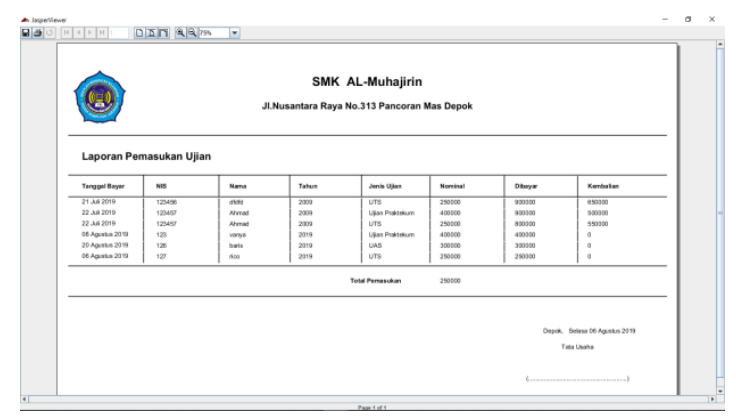

Gambar 16. Output Laporan Data Pembayaran Ujian

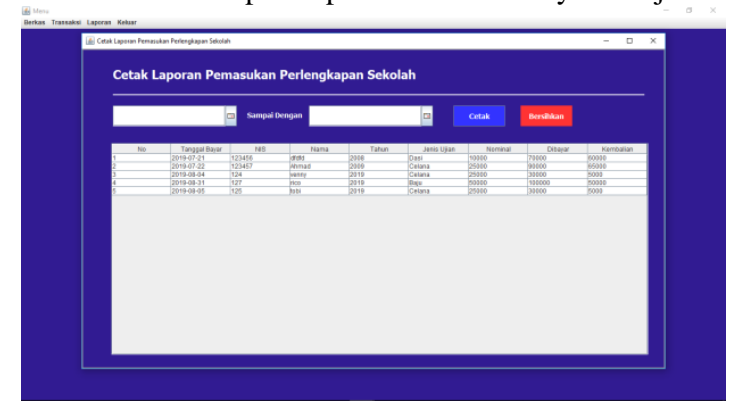

Gambar 17. Tampilan Laporan Pemasukan Perlengkapan Sekolah

Tampilan Laporan data pembayaran perlengkapan Sekolah, user akan memilih tanggal laporan data pembayaran perlengkapan sekolah yang akan diserahkan kepada kepala sekolah, untuk mencetak data klik tombol (cetak) dan untuk menghapus data klik tombol (bersihkan) .

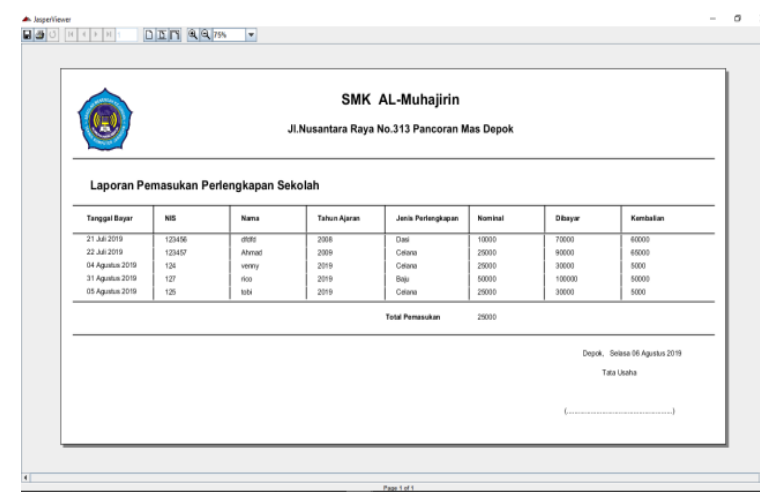

Gambar 18. Output Laporan Pemasukan Perlengkapan Sekolah

\section{Kesimpulan}

Dari pembahasan bab-bab sebelumnya, peneliti dapat menarik kesimpulan bahwa :

1. Memberikan kemudahan untuk mengolah sebuah data menjadi informasi yang mudah di akses .

2. Sistem administrasi keuangan pada SMK Al-Muhajirin Depok menjadi lebih berkualitas, cepat dan akurat.

3. Aplikasi sistem administrasi keuangan dapat memberikan keamanan untuk mengantisipasi hal-hal yang tidak diinginkan seperti kehilangan berkas. Karena dengan adanya aplikasi ini, data dapat disimpan pada memory seperti cloud drive, hard drive computer dan flashdisk.

\section{Daftar Pustaka}

Fristanto, H. T. (2013). Rancang Bangun Sistem Informasi Pembayaran Sumbangan Pembinaan Pendidikan (Spp) Dan Insidental Pada Sekolah Menengah Kejuruan Muhammadiyah Tinatar Punung. Indonesian Journal on Networking and Security, 3(4), 24-28.

Sugiyono. (2013). Metode Penelitian Manajemen. Alfabeta.

Sutabri, T. (2016). Sistem Informasi Manajemen. Andi Offset, CV.

Yakub. (2012). Pengantar Sistem Inormasi. Graha Ilmu.

Yanto, R. (2016). Manajemen Basis Data Menggunakan MySQL. Deepublish. 